\title{
Advances in Electron-probe Microanalysis and Problem-Solving Approaches Using Microanalysis Tools
}

\author{
P.K. Carpenter* \\ *Department of Earth and Planetary Sciences, CB 1169, Washington University, Saint Louis, \\ MO, 63130
}

Advances in electron-probe microanalysis (EPMA) include improvements in microprobe operating system components, measurement capabilities, correction algorithms, and tools used to support microanalysis. EPMA of a lunar keiviite-(Y) is an example where advances in microanalysis and the use of analysis tools are used to improve understanding and accuracy of the analysis problem. Keviite-(Y) has a nominal composition (Y,REE) ${ }_{2} \mathrm{Si}_{2} \mathrm{O}_{7}$ and to date has been observed only in terrestrial rocks. A small $(3 \times 10 \mu \mathrm{m})$ crystal of keiviite-(Y) has been discovered in Apollo troctolitic anorthosite 76335, where it is in contact with RE-merrillite (a lunar REE bearing Caphosphate, Fig. 1) [1]. Terrestrial rare-earth element (REE) minerals exhibit significant substitution of REE for yttrium, and form carbonate, phosphate, and silicate minerals. Lunar rocks contain a chemical component known as KREEP and RE-merrillite is a typical mineral that exhibits REE enrichment, and REE silicates are previously unknown on the Moon. Lunar REE-bearing minerals (e.g., zirconolite) may contain uranium, thorium, and (due to the great age) radiogenic lead. As a result of radioactivity, these minerals are metamict and attempts to obtain EBSD patterns have not been successful. As a result it is necessary to use compositional and spatial analysis to confirm the mineral identity.

Because the lunar keiviite-(Y) is small and variable in thickness, partial sampling of the REmerrillite is unavoidable and the initial keiviite-(Y) analysis contained $\mathrm{Ca}$ and P. DTSA-II was used to simulate a $1.5 \mu \mathrm{m}$ inclusion of $\mathrm{Ca}$ and $\mathrm{P}$-free keiviite-(Y) embedded in RE-merrillite and modeling confirms that the $\mathrm{Ca}$ and $\mathrm{P}$ are not in the keiviite-( $\mathrm{Y})$ but rather produced by primary electron scattering and secondary $x$-ray fluorescence of RE-merrillite (Fig. 2) [2]. The DTSA-II tool is thus crucial to identification of the element inventory in the keiviite-(Y). Lunar REmerrillite exhibits light REE enrichment, and the lunar keiviite-(Y) exhibits heavy REE enrichment, thus requiring an analytical setup for all REE in a microprobe run. EPMA of REE minerals is challenging due to significant peak interferences which complicates EDS and WDS identification as well as selection of WDS background measurement locations (Fig. 4).

Several EPMA capabilities of the Probe for EPMA (PFE) software were used to analyze this important sample [2]. A suite of REE standards was used to determine the internal consistency of accepted analyses, and to evaluate peak interferences for the formal PFE interference correction. WDS measurements using conventional background offsets were compared with the PFE mean atomic number (MAN) empirical background calibration (Fig 3). Multiple WDS measurement was performed for both improved trace element analysis and redundant verification of the analysis. The interference correction allows measurement of REE concentrations from essentially zero to the REE content of primary standards. These capabilities allow the measurement of all naturally occurring REE in one sample setup, and the capability to use a diverse set of REE standards 
for correction and cross-checking. The resulting formula for the lunar keiviite-(Y) is $\left(\mathrm{Y}_{1.4} \mathrm{REE}_{0.43} \mathrm{Mg}_{0.09} \mathrm{Fe}_{0.06} \mathrm{~Pb}_{0.01} \mathrm{Th}_{0.01}\right) \mathrm{Si}_{2} \mathrm{O}_{7}$.

Many advances in instrumentation and microprobe analysis software have been made since Castaing's first development of the instrument; indeed originally there was neither automation nor an operating system. Sophisticated sample setups allow for element lists, analytical conditions, count times, and primary standards customized on a per sample basis and represents a major step forward in analytical flexibility. Simultaneous measurement of trace elements using multiple WDS can improve the detection limit by at least one order of magnitude. Time-based measurement on beam-sensitive materials allows a regression to zero time to correct for element migration or other processes. Treatment of WDS background has seen major advances with a choice of linear or non-linear (e.g., polynomial) background measurement with more advanced capabilities now available. Use of a mean-atomic number (MAN) set of empirically determined background intensities allows a significant reduction in analysis time, verification of conventional off-peak background measurement, and/or avoidance of complex background measurement. These are all capabilities that have resulted from the needs of analysts, in the same way that Castaing originally developed the electron microprobe to enable analysis of micro-inclusions.

\section{References}

[1] Carpenter, P. et al. (2011) LPS XXXXII, submitted.

[2] NIST DTSA-II

[3] Probe Software Inc.
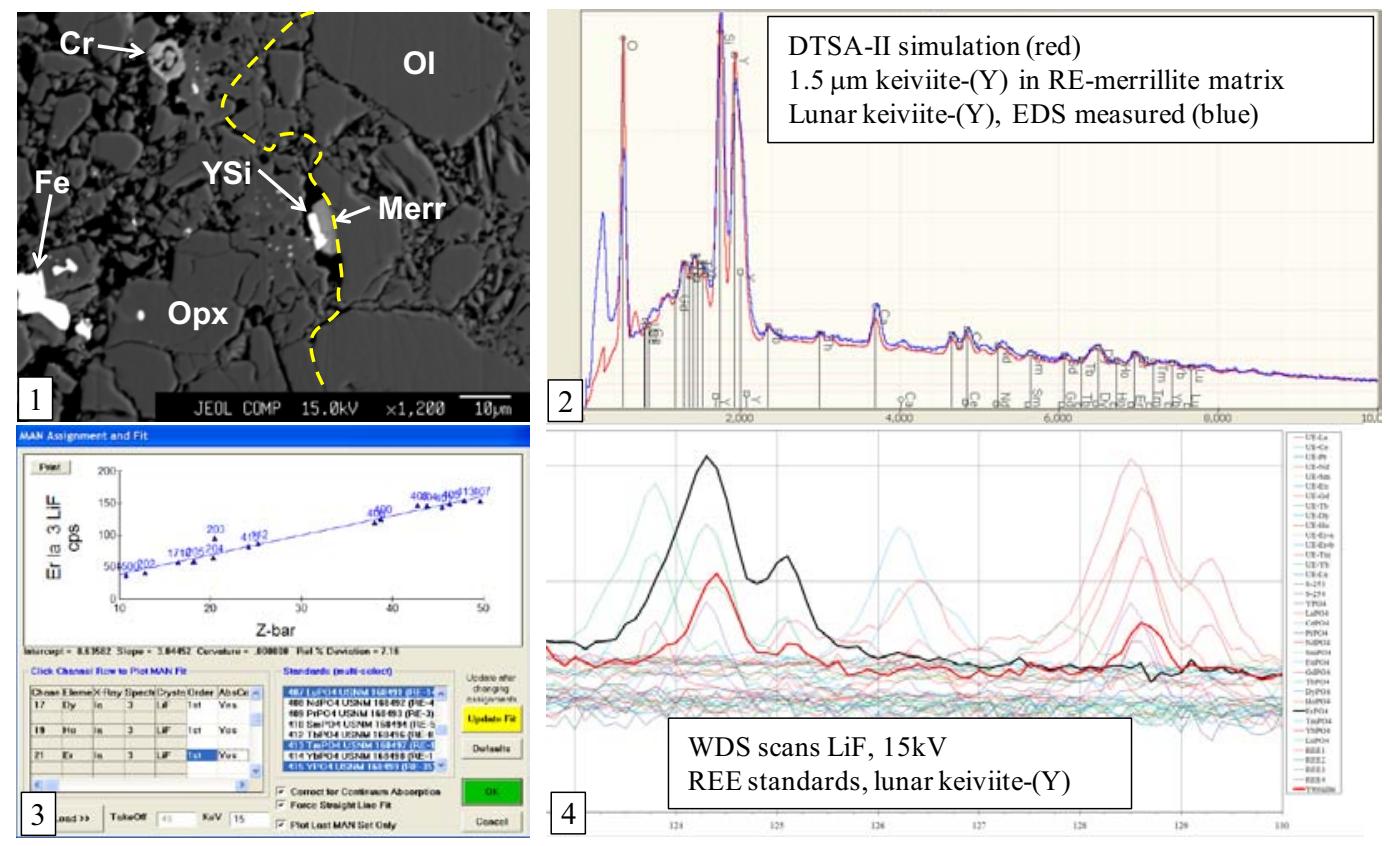

FIG 1. Backscattered-electron image of lunar keiviite-(Y) (label YSi) and RE-merrillite (label Merr). FIG 2. Comparison of observed keiviite-(Y) EDS with simulated $1.5 \mathrm{~mm}$ cubic inclusion of Ca and P-free keiviite-(Y) in RE-merrillite matrix.

FIG 3. Dialog for MAN assignment of Er L $\alpha$ empirical backgrounds, showing fit to all MAN standards. FIG 4. Wavelength scans using LiF crystal, centered at Er L $\alpha$ position for all REE standards and lunar keiviite(Y). Highlighted: $\mathrm{ErPO}_{4}$ standard in black, keiviite-(Y) in red. Logarithmic intensity scale. 